\title{
Divergência genética de milho transgênico em relação à produtividade de grãos e à qualidade nutricional
}

\author{
Genetic divergence of transgenic maize in relation to grain productivity and nutritional quality
}

\author{
Bruna Mendonça Alves ${ }^{\mathrm{I}}$ Alberto Cargnelutti Filho ${ }^{\mathrm{I} *}$ Cláudia Burin $^{\mathrm{II}}$ Marcos Toebe $^{\mathrm{II}}$ \\ Leila Picolli da Silva ${ }^{\text {III }}$
}

\section{RESUMO}

O objetivo deste trabalho foi verificar a divergência genética entre genótipos de milho transgênico, em relação à produtividade de grãos e à qualidade nutricional. O experimento foi conduzido na safra 2009/2010, em Santa Maria, Estado do Rio Grande do Sul, no delineamento blocos casualizados, com três repetições. Foram avaliados 18 genótipos e mensuradas as seguintes variáveis após a colheita: produtividade de grãos, proteina bruta, lisina, metionina, cisteina, treonina, triptofano, valina, isoleucina, leucina, fenilalanina, histidina, arginina, extrato etéreo, amido e amilose. Para cada variável, foi realizada a análise de variância e comparadas as médias por meio do teste de Scott-Knott. Foi determinada a matriz de coeficientes de correlação genotípica e realizado o diagnóstico de multicolinearidade. Foi determinada a matriz de dissimilaridade entre os genótipos por meio da distância generalizada de Mahalanobis, realizado o agrupamento dos genótipos por meio do método UPGMA e validado o agrupamento por meio do coeficiente de correlação cofenética. Foram comparadas as médias dos grupos por meio do teste t para amostras independentes. Há divergência genética entre os genótipos de milho transgênico. As variáveis amilose, extrato etéreo e cisteina foram, nessa ordem, as que mais contribuíram para a divergência genética. Com base na produtividade de grãos, proteina bruta, lisina, cisteina, triptofano, extrato etéreo e amilose, há quatro grupos de genótipos de milho transgênico.

Palavras-chave: Zea mays L., variabilidade genética, análise de agrupamento.

\section{ABSTRACT}

The aim of this study was to investigate the genetic divergence between genotypes of transgenic maize, in relation to grain productivity and nutritional quality. The experiment was conducted in 2009/2010 in Santa Maria, State of Rio Grande do

\begin{abstract}
Sul, on randomized block design with three replicates. Eighteen genotypes were analyzed and the variables were measured after harvest: grain productivity, crude protein, lysine, methionine, cysteine, threonine, tryptophan, valine, isoleucine, leucine, phenylalanine, histidine, arginine, ethereal extract, starch and amylose. An analysis of variance was performed for each variable and the means were compared using the Scott-Knott test. The genotypic correlation matrix was calculated, multicollinearity was evaluated and a contribution analysis was performed. Dissimilarity matrix between genotypes was determined by Mahalanobis generalized distance. The genotypes were grouped using the Unweighted Pair Group Method with Arithmetic Mean (UPGMA) and the cophenetic correlation coefficient was calculated to validate the grouping. The group means were compared using the t-test for independent samples. There is genetic divergence between genotypes of transgenic maize. Variables amylose, ethereal extract and cysteine showed the greatest contribution to genetic divergence. Based on grain productivity, crude protein, lysine, cysteine, tryptophan, ethereal extract and amylase, there are four genotype groups of transgenic maize.
\end{abstract}

Key words: Zea mays L., genetic variability, cluster analysis.

\section{INTRODUÇ̃̃O}

O milho (Zea mays L.) é o principal ingrediente energético destinado à nutrição animal, especialmente a de não ruminantes, como aves e suínos, pois apresenta alta digestibilidade de seus nutrientes, seguido por ausência de fatores antinutricionais intrínsecos e de elevada produtividade de grãos. Por esse motivo, 70 a $80 \%$ da produção deste cereal é

'Programa de Pós-graduação em Agronomia, Universidade Federal de Santa Maria (UFSM), Santa Maria, RS, Brasil.

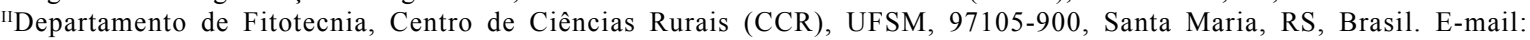
alberto.cargnelutti.filho@gmail.com.*Autor para correspondência.

IIIDepartamento de Zootecnia, CCR, UFSM, Santa Maria, RS, Brasil. 
diretamente convertida em rações para produção de proteína de origem animal (carne, leite, ovos).

O mercado da nutrição animal exige alta qualidade sanitária de produtos a fim de maximizar a produtividade dos sistemas. Diante disso, o controle de pragas no cultivo de milho é fator preponderante para garantir sua qualidade e valor de mercado, o que tem alavancado novas tecnologias, como a transgenia, criando variedades tolerantes a herbicidas ou resistentes a insetos (COLLI, 2011). Visando ao aumento da sustentabilidade no meio rural, muitos produtores já usufruem dos benefícios do milho transgênico, buscando maximizar a produtividade das lavouras, reduzir custos de produção e diminuir a aplicação de agrotóxicos (QAIM \& MATUSCHKE, 2005).

O milho é cultivado em todos os estados do Brasil, sendo a sua produção concentrada nas Regiões Sul, Centro-Oeste e Sudeste. Os estados, do Paraná, Mato Grosso, Rio Grande do Sul e Minas Gerais contribuem com $51,04 \%$ da produção brasileira, a qual tem apresentado tendência de elevação, desde o fim da década de 80 (CALDARELLI \& BACCHI, 2012), pelo aumento exponencial de sua demanda, devido à elevação na produção de carne no País.

Embora a transgenia tenha sido intensamente aplicada para melhoria das características agronômicas deste cereal, poucos estudos foram desenvolvidos a fim de atender necessidades iminentes de seu principal mercado consumidor, a nutrição animal, que necessita de melhorias nutricionais em ingredientes usados em grande escala para formulação de rações, o que trará redução de custos na inserção de fontes purificadas (ex. aminoácidos isolados). Neste cenário, estudos sobre a composição proteica, especialmente relacionada ao perfil de aminoácidos, e a composição de moléculas de amido, podem ter impactos importantes na nutricional animal.

Nos programas de melhoramento genético de milho, é importante visar ao aumento da produtividade de grãos sem comprometer a qualidade nutricional e a constituição do grão, tanto em cultivares transgênicas como em convencionais. Além disso, a composição proteica e aminoacídica dos grãos têm influência do genótipo, do ambiente e da interação entre esses fatores (ZHU \& KHAN, 2001). Com isso, não é possível afirmar que cultivares transgênicas apresentam melhor qualidade nutricional quando comparadas às cultivares convencionais.

$\mathrm{O}$ estudo da diversidade genética com auxílio da análise multivariada é importante para os programas de melhoramento genético, pois a variabilidade existente entre os genótipos é uma estratégia para obter ganhos de seleção nos cruzamentos de grupos geneticamente divergentes, que apresentam características de interesse (CRUZ \& CARNEIRO, 2006). Estudos sobre a divergência genética, por meio de análise multivariada foram realizados na cultura de milho por DOTTO et al. (2010), ROTILI et al. (2012) e SIMON et al. (2012).

A distância generalizada de Mahalanobis $\left(D^{2}\right)$ é apropriada para medir a distância genética entre os genótipos, por considerar as correlações entre os caracteres e pode ser estimada a partir de experimentos com repetições (CRUZ \& CARNEIRO, 2006). Dentre os métodos hierárquicos para a análise de agrupamento, o UPGMA tem sido utilizado em estudos de divergência genética em milho (SUBRAMANIAN \& SUBBARAMAN, 2010; IDRIS et al., 2012; SIMON et al., 2012) e, conforme CARGNELUTTI FILHO \& GUADAGNIN (2011), foi considerado o método mais eficiente no agrupamento de cultivares de milho.

Diante do exposto, o objetivo do presente trabalho foi verificar a divergência genética entre genótipos de milho transgênico, em relação à produtividade de grãos e à qualidade nutricional.

\section{MATERIAL E MÉTODOS}

Foi conduzido um experimento com a cultura de milho (Zea mays L.), na área experimental do Departamento de Fitotecnia, da Universidade Federal de Santa Maria, Estado do Rio Grande do Sul (RS), a $29^{\circ} 42^{\prime} \mathrm{S}, 53^{\circ} 49^{\prime} \mathrm{W}$ e a $95 \mathrm{~m}$ de altitude, no ano agrícola 2009/2010. Foram avaliados 18 genótipos de milho transgênico, no delineamento experimental blocos ao acaso, com três repetições. Os genótipos pertenciam à rede de ensaios de competição de cultivares de milho, do RS. A relação dos genótipos que compuseram o experimento foi determinada pela Fundação Estadual de Pesquisa Agropecuária (FEPAGRO), que coordena a rede de ensaios de avaliação de cultivares de milho do RS. As unidades experimentais foram compostas de duas fileiras com $5 \mathrm{~m}$ de comprimento, espaçadas em $0,80 \mathrm{~m}$ entre fileira e $0,20 \mathrm{~m}$ entre plantas na fileira. A semeadura da cultura foi realizada manualmente, em 26 de outubro de 2009, com adubação de base de $37,5 \mathrm{~kg} \mathrm{ha}^{-1}$ de nitrogênio (N), $150 \mathrm{~kg} \mathrm{ha}^{-1}$ de fósforo $\left(\mathrm{P}_{2} \mathrm{O}_{5}\right)$ e $150 \mathrm{~kg} \mathrm{ha}^{-1} \mathrm{de}$ potássio $\left(\mathrm{K}_{2} \mathrm{O}\right)$. A emergência das plantas ocorreu entre 01 e 03 de novembro de 2009 e a população foi ajustada para 62.500 plantas ha- ${ }^{-1}$. Em cobertura, 
foram aplicados $200 \mathrm{~kg} \mathrm{ha}^{-1}$ de nitrogênio, divididos em três aplicações, quando as plantas apresentaram três, cinco e dez folhas.

A colheita de grãos foi realizada no dia 15 de março de 2010. Depois, para cada repetição de cada genótipo, determinou-se a umidade dos grãos e a produtividade (PROD, em t ha ${ }^{-1}$ ) com peso corrigido para $13 \%$ de umidade. Posteriormente, de cada parcela, separou-se uma amostra de 500 gramas de grãos de milho, que foi acondicionada em um saco de papel e levada à estufa de circulação forçada de ar até atingir umidade média de 10\%. Após a secagem, os grãos foram moídos em micromoinho (MA-630, Marconi), a fim de obter uma amostra com granulometria entre 0,30 e $0,50 \mathrm{~mm}$. Cada amostra moída foi acondicionada em embalagem hermeticamente fechada até o momento das análises nutricionais dos grãos. Foram avaliadas as variáveis: proteína bruta (PB), lisina (LIS), metionina (MET), cisteina (CIS), treonina (THR), triptofano (TRP), valina (VAL), isoleucina (ILE), leucina (LEU), fenilalanina (FEN), histidina (HIS), arginina (ARG), extrato etéreo (EE), amido (AMD) e amilose (AML), todas em porcentagem da matéria bruta (\%MB). As avaliações foram realizadas por meio de Espectroscopia de Refletância no Infravermelho Próximo (NIR -Near Infrared Reflectance), usando ajuste de calibração pelo procedimento analítico CEAN 010 da Adisseo Brasil AS. O teor de amilose foi determinado conforme técnica iodométrica descrita por MARTINEZ \& CUEVASPEREZ (1989), seguindo as etapas de dissolução, gelatinização, acidificação e adição de solução de iodo para complexação com o amido e leitura em espectrofotômetro a $620 \mathrm{~nm}$.

Inicialmente, verificou-se a normalidade dos erros, por meio do teste de KolmogorovSmirnov (CAMPOS, 1983) e a homogeneidade das variâncias residuais entre os tratamentos, pelo teste de Levene (STEEL et al., 1997). Depois, foi realizada a análise de variância e as médias dos genótipos foram comparadas pelo teste de ScottKnott, a $5 \%$ de probabilidade. As variáveis que não apresentaram diferenças significativas, a 5\% de probabilidade, pelo teste $\mathrm{F}$ da análise de variância, não foram incluídas na análise de agrupamento. Com as variáveis que apresentaram diferenças significativas pelo teste $\mathrm{F}$, calculou-se a matriz de correlação genotípica e procedeu-se ao diagnóstico de multicolinearidade.

O grau de multicolinearidade da matriz de correlação genotípica foi avaliado com base no número de condição (NC), que é a razão entre o maior e o menor autovalor da matriz de correlação. Utilizou-se, como critério de decisão, a classificação proposta por MONTGOMERY \& PECK (1982) e descrita por CRUZ \& CARNEIRO (2006). Assim, se o número de condição $(\mathrm{NC})$ foi $\mathrm{NC} \leq 100$, considerou-se multicolinearidade fraca entre as variáveis, se $100<\mathrm{NC}<1.000$, multicolinearidade moderada a forte e se $\mathrm{NC} \geq 1.000$, multicolinearidade severa. No caso de multicolinearidade moderada a forte ou severa, procedeu-se à eliminação de variáveis altamente correlacionadas. A seguir, foi calculada a contribuição relativa de cada variável para a divergência genética, conforme método proposto por SINGH (1981).

A matriz de distância generalizada de Mahalanobis $\left(\mathrm{D}^{2}\right)$ entre os genótipos, em escala relativa, foi utilizada como medida de dissimilaridade para a análise de agrupamento pelo método hierárquico da ligação média entre grupos (UPGMA - Unweighted Pair Group Method with Arithmetic Mean) (CRUZ, 2013). Posteriormente, foi construído o dendrograma, calculado o coeficiente de correlação cofenética (CCC) e realizado o corte no dendrograma, usando como critério $70 \%$ de dissimilaridade. Esse percentual foi definido em $70 \%$, pois grande mudança de nível na distância de agrupamento indica a união de genótipos heterogêneos (BARROSO \& ARTES, 2003). Assim, adotou-se $70 \%$ em função da mudança abrupta de nível. Após, por meio de 10.000 reamostragens bootstrap, foi estimada a consistência das bifurcações, em \% (CRUZ, 2013). Depois, foram calculadas as médias, de cada variável, em cada grupo e, posteriormente, para a validação do agrupamento, as médias dos grupos foram comparadas, duas a duas, pelo teste t de Student para amostras independentes. As análises estatísticas foram realizadas com auxílio dos softwares GENES (CRUZ, 2013) e Bioestat 5.0 (AYRES et al., 2007) e do aplicativo Office Excel ${ }^{\circledR}$.

\section{RESULTADOS E DISCUSSÃO}

Após a aplicação do teste KolmogorovSmirnov, verificou-se que, com exceção do triptofano (TRP), os resíduos das demais 15 variáveis ajustaram-se à distribuição normal. Para a pressuposição de homogeneidade das variâncias residuais, pelo teste de Levene, verificou-se que, para todas as variáveis mensuradas, esse pressuposto foi atendido (Tabela 1). Assim, com base na análise de variância, houve efeitos significativos de genótipos, a $5 \%$ de probabilidade pelo teste $\mathrm{F}$, para 14 das 16 
Tabela 1 - Resumo da análise de variância [número de graus de liberdade (GL) e quadrado médio para as fontes de variação bloco, genótipos e erro], média, coeficiente de variação experimental (CV\%), acurácia seletiva (AS), precisão experimental e os resultados dos testes de normalidade dos erros pelo teste de Kolmogorov-Smirnov e homogeneidade de variâncias residuais pelo teste de Levene, para um experimento com 18 genótipos de milho transgênico.

\begin{tabular}{|c|c|c|c|c|c|c|c|c|c|}
\hline \multirow{2}{*}{ FV } & \multirow{2}{*}{ GL } & \multicolumn{8}{|c|}{ veis $^{(1)}$} \\
\hline & & PROD & $\mathrm{PB}$ & LIS & MET & CIS & THR & TRP & VAL \\
\hline Bloco & 2 & 0,185962 & 0,052689 & 0,000057 & 0,000146 & 0,000039 & 0,000517 & 0,00003 & 0,000524 \\
\hline Genótipo & 17 & $1,212095^{*}$ & $0,303255^{*}$ & $0,000156^{*}$ & $0,000049^{\text {ns }}$ & $0,000153 *$ & $\begin{array}{l}0,000664 \\
*\end{array}$ & $0,000058^{*}$ & $0,000662 *$ \\
\hline Erro & 34 & 0,441951 & 0,097841 & 0,000026 & 0,000026 & 0,000024 & 0,0001 & 0,000012 & 0,00015 \\
\hline Média & - & 6,69 & 7,63 & 0,21 & 0,14 & 0,17 & 0,21 & 0,05 & 0,29 \\
\hline $\mathrm{CV}(\%)$ & - & 9,94 & 4,1 & 2,4 & 3,61 & 2,93 & 4,8 & 7,5 & 4,26 \\
\hline AS & - & 0,80 & 0,82 & 0,91 & 0,68 & 0,92 & 0,92 & 0,89 & 0,88 \\
\hline Precisão ${ }^{(2)}$ & & A & A & MA & $\mathrm{M}$ & MA & MA & A & A \\
\hline Normalidade ${ }^{(3)}$ & & $\mathrm{N}$ & $\mathrm{N}$ & $\mathrm{N}$ & $\mathrm{N}$ & $\mathrm{N}$ & $\mathrm{N}$ & $\mathrm{NN}$ & $\mathrm{N}$ \\
\hline \multirow[t]{2}{*}{ Homogeneidade $^{(4)}$} & & $\mathrm{H}$ & $\mathrm{H}$ & $\mathrm{H}$ & $\mathrm{H}$ & $\mathrm{H}$ & $\mathrm{H}$ & $\mathrm{H}$ & $\mathrm{H}$ \\
\hline & & ILE & LEU & FEN & HIS & ARG & $\mathrm{EE}$ & AMD & AML \\
\hline Bloco & 2 & 0,00045 & 0,007724 & 0,001257 & 0,000057 & 0,000467 & 0,00005 & 2,512439 & 1,809252 \\
\hline Genótipo & 17 & $0,000468^{*}$ & $0,005584 *$ & $0,001021^{*}$ & $0,000563^{*}$ & $0,000675^{*}$ & $\begin{array}{l}0,061851 \\
*\end{array}$ & $2,94592^{\mathrm{ns}}$ & $5,904131^{*}$ \\
\hline Erro & 34 & 0,000097 & 0,001594 & 0,000215 & 0,00005 & 0,000076 & 0,007071 & 1,768297 & 0,376494 \\
\hline Média & - & 0,18 & 0,79 & 0,26 & 0,18 & 0,33 & 3,72 & 69,43 & 29,69 \\
\hline $\mathrm{CV}(\%)$ & - & 5,63 & 5,07 & 5,57 & 3,85 & 2,65 & 2,26 & 1,92 & 2,07 \\
\hline AS & - & 0,89 & 0,85 & 0,89 & 0,95 & 0,94 & 0,94 & 0,63 & 0,97 \\
\hline Precisão ${ }^{(2)}$ & & A & A & A & MA & MA & MA & M & MA \\
\hline Normalidade $^{(3)}$ & & $\mathrm{N}$ & $\mathrm{N}$ & $\mathrm{N}$ & $\mathrm{N}$ & $\mathrm{N}$ & $\mathrm{N}$ & $\mathrm{N}$ & $\mathrm{N}$ \\
\hline Homogeneidade ${ }^{(4)}$ & & $\mathrm{H}$ & $\mathrm{H}$ & $\mathrm{H}$ & $\mathrm{H}$ & $\mathrm{H}$ & $\mathrm{H}$ & $\mathrm{H}$ & $\mathrm{H}$ \\
\hline
\end{tabular}

${ }^{(1)}$ PROD: produtividade de grãos $\left(\mathrm{t} \mathrm{ha}^{-1}\right), \mathrm{PB}$ : proteína bruta $(\% \mathrm{MB})$, LIS: lisina $(\% \mathrm{MB})$, MET: metionina (\%MB), CIS: cisteina $(\% \mathrm{MB})$, THR: treonina (\%MB), TRP: triptofano $(\% \mathrm{MB})$, VAL: valina $(\% \mathrm{MB})$, ILE: isoleucina (\%MB), LEU: leucina (\%MB), FEN: fenilalanina $(\% \mathrm{MB})$, HIS: histidina $(\% \mathrm{MB})$, ARG: arginina (\%MB); EE: extrato etéreo (\%MB); AMD: amido (\%MB) e AML: amilose (\%MB). ${ }^{*}$ Efeito significativo pelo teste $\mathrm{F}$ a $5 \%$ de probabilidade. ${ }^{\text {ns }}$ não significativo. ${ }^{(2)}$ Limites de classes estabelecidos por RESENDE \& DUARTE (2007), sendo, MA: muito alta $(\mathrm{AS}=0,90)$, A: alta $(0,70=\mathrm{AS}<0,90)$, M: moderada $(0,50=\mathrm{AS}<0,70)$ e, B: baixa $(\mathrm{AS}<0,50) .{ }^{(3)} \operatorname{Resultado}$ do teste de Kolmogorov-Smirnov para normalidade da distribuição dos erros. N - normal; NN -não-normal. ${ }^{(4)}$ Resultado do teste de Levene para homogeneidade de variâncias residuais. H - homogêneas; NH -não-homogêneas.

variáveis mensuradas, com exceção das variáveis MET e AMD, que não diferiram estatisticamente entre os genótipos (Tabela 1). Portanto, podese inferir que há variabilidade genética, o que possibilita o estudo da divergência genética entre os genótipos de milho transgênico por meio de técnicas multivariadas.

As variáveis MET e AMD, sem diferença significativa entre os genótipos, apresentaram os menores escores de acurácia seletiva (AS), com valores de 0,68 e 0,63, respectivamente, o que confere moderada precisão experimental, e não foram incluídas na análise de agrupamento. Observou-se que $87,5 \%$ das varáveis apresentaram AS superior a 0,70 , conferindo precisão experimental de alta a muito alta e apenas $12,5 \%$ das variáveis apresentaram AS inferior a 0,70 (Tabela 1). Os coeficientes de variação (CV) foram baixos (inferiores a 10,0\%) para todas as variáveis mensuradas, sendo a variável PROD (CV=9,94\%) a que apresentou o maior CV. Portanto, de maneira geral, a elevada precisão experimental confere credibilidade às inferências deste estudo.

A média da produtividade de grãos (PROD) dos genótipos transgênicos foi de 6,69t ha $^{-1}$ (Tabela 1) e oscilou de 5,58 a 7,64t ha-1 para os genótipos P30F36Y e DKB566YG, respectivamente, demonstrando elevado potencial produtivo de genótipos transgênicos, quando comparado aos genótipos convencionais (Tabela 2). Trabalho realizado por ALVES et al. (2014) mostrou que, nas mesmas condições de cultivo e no mesmo ano agrícola em que foram avaliadas essas cultivares transgênicas, as cultivares de ciclos precoces e superprecoces (não transgênicas), obtiveram produtividades médias de $5,0 \mathrm{t} \mathrm{ha} \mathrm{h}^{-1}$ e 5,92t ha-1, respectivamente. SIMON et al. 
Tabela 2 - Médias de produtividade de grãos (PROD) em $\mathrm{t} \mathrm{ha}^{-1}$, proteína bruta (PB) em percentagem da matéria bruta (\%MB), lisina (LIS, em \%MB), metionina (MET, em \%MB), cisteina (CIS, em \%MB), treonina (THR, em \%MB), triptofano (TRP, em \%MB), valina (VAL, em \%MB), isoleucina (ILE, em \%MB), leucina (LEU, em \%MB), fenilalanina (FEN, em \%MB), histidina (HIS, em $\% \mathrm{MB}$ ), arginina (ARG, em \%MB), extrato etéreo (EE, em \%MB), amido (AMD, em \%MB) e amilose (AML, em \%MB) de 18 genótipos de milho transgênico, obtidos na safra 2009/2010.

\begin{tabular}{|c|c|c|c|c|c|c|c|c|}
\hline \multirow{2}{*}{ Genótipo } & \multicolumn{8}{|c|}{ - } \\
\hline & PROD & PB & LIS & MET & CIS & THR & TRP & VAL \\
\hline AS1551YG & $6,2363 b^{*}$ & $7,9267 \mathrm{a}$ & $0,2233 a$ & $0,1433^{\mathrm{ns}}$ & $0,1733 a$ & $0,2300 \mathrm{a}$ & $0,0500 \mathrm{a}$ & $0,2967 b$ \\
\hline AS1555YG & $6,1232 b$ & $7,7333 a$ & $0,2200 \mathrm{a}$ & 0,1433 & $0,1633 b$ & $0,2200 \mathrm{a}$ & $0,0500 \mathrm{a}$ & $0,2933 b$ \\
\hline AS1572YG & $6,2571 b$ & $7,5867 b$ & $0,2200 \mathrm{a}$ & 0,1500 & $0,1533 c$ & $0,2167 b$ & $0,0500 \mathrm{a}$ & $0,2833 b$ \\
\hline AS1573YG & $7,3846 a$ & $6,9733 b$ & $0,1967 \mathrm{c}$ & 0,1367 & $0,1533 c$ & $0,1767 \mathrm{c}$ & $0,0367 b$ & $0,2600 \mathrm{c}$ \\
\hline AS1578YG & $6,7538 \mathrm{a}$ & $7,6100 \mathrm{~b}$ & $0,2200 \mathrm{a}$ & 0,1467 & $0,1667 b$ & $0,2133 b$ & $0,0500 \mathrm{a}$ & $0,2900 b$ \\
\hline DKB240YG & $7,6320 \mathrm{a}$ & $7,4033 b$ & $0,2067 b$ & 0,1367 & $0,1667 b$ & $0,1867 \mathrm{c}$ & $0,0400 \mathrm{~b}$ & $0,2700 \mathrm{c}$ \\
\hline DKB566YG & $7,6427 \mathrm{a}$ & $7,2633 b$ & $0,2167 \mathrm{a}$ & 0,1400 & $0,1633 b$ & $0,2100 \mathrm{~b}$ & $0,0433 b$ & $0,2867 b$ \\
\hline 2B604HX & $5,7498 b$ & $8,0900 \mathrm{a}$ & $0,2200 \mathrm{a}$ & 0,1467 & $0,1700 \mathrm{~b}$ & $0,2300 \mathrm{a}$ & $0,0500 \mathrm{a}$ & $0,3167 \mathrm{a}$ \\
\hline P30B39Y & $5,9686 b$ & $7,5567 b$ & $0,2133 a$ & 0,1400 & $0,1667 b$ & $0,2100 \mathrm{~b}$ & $0,0500 \mathrm{a}$ & $0,2867 b$ \\
\hline P30F36Y & $5,5790 \mathrm{~b}$ & $7,8967 \mathrm{a}$ & $0,2167 \mathrm{a}$ & 0,1433 & $0,1667 b$ & $0,2033 \mathrm{c}$ & $0,0467 \mathrm{a}$ & $0,2867 b$ \\
\hline P30F53Y & $7,4081 \mathrm{a}$ & $8,0233 a$ & $0,2100 \mathrm{~b}$ & 0,1367 & $0,1700 \mathrm{~b}$ & $0,2067 b$ & $0,0467 \mathrm{a}$ & $0,2867 b$ \\
\hline P30F53H & $6,7991 \mathrm{a}$ & $7,5367 b$ & $0,2133 \mathrm{a}$ & 0,1400 & $0,1667 b$ & $0,2100 \mathrm{~b}$ & $0,0467 \mathrm{a}$ & $0,2933 b$ \\
\hline P32R48Y & $6,5242 b$ & $7,8067 \mathrm{a}$ & $0,2200 \mathrm{a}$ & 0,1467 & $0,1700 \mathrm{~b}$ & $0,2267 \mathrm{a}$ & $0,0500 \mathrm{a}$ & $0,3067 \mathrm{a}$ \\
\hline BG7060Y & $7,1303 \mathrm{a}$ & $7,7167 \mathrm{a}$ & $0,2167 \mathrm{a}$ & 0,1467 & $0,1767 \mathrm{a}$ & $0,2200 \mathrm{a}$ & $0,0467 \mathrm{a}$ & $0,3067 \mathrm{a}$ \\
\hline AG8011YG & $6,4823 b$ & $7,2833 b$ & $0,2167 \mathrm{a}$ & 0,1433 & $0,1600 \mathrm{c}$ & $0,1967 \mathrm{c}$ & $0,0400 \mathrm{~b}$ & $0,2700 \mathrm{c}$ \\
\hline AG9020YG & $6,4950 \mathrm{~b}$ & $7,2400 \mathrm{~b}$ & $0,2100 \mathrm{~b}$ & 0,1467 & $0,1633 b$ & $0,2067 b$ & $0,0433 b$ & $0,2867 b$ \\
\hline BG8124YG & $7,2405 \mathrm{a}$ & $7,5967 b$ & $0,2000 \mathrm{c}$ & 0,1400 & $0,1533 \mathrm{c}$ & $0,1900 \mathrm{c}$ & $0,0400 \mathrm{~b}$ & $0,2633 \mathrm{c}$ \\
\hline BG8418YG & $7,0074 \mathrm{a}$ & $8,1167 \mathrm{a}$ & $0,2167 \mathrm{a}$ & 0,1400 & $0,1767 \mathrm{a}$ & $0,1967 \mathrm{c}$ & $0,0433 b$ & $0,2933 b$ \\
\hline \multirow[t]{2}{*}{ Número de grupos } & 2 & 2 & 3 & - & 3 & 3 & 2 & 3 \\
\hline & ILE & LEU & FEN & HIS & ARG & $\mathrm{EE}$ & AMD & AML \\
\hline AS1551YG & $0,1867 \mathrm{a}$ & $0,8100 \mathrm{a}$ & $0,2767 \mathrm{a}$ & $0,1900 \mathrm{~b}$ & $0,3467 \mathrm{a}$ & $3,6733 b$ & $69,5400^{\mathrm{ns}}$ & $30,0867 b$ \\
\hline AS1555YG & $0,1833 a$ & $0,7700 \mathrm{~b}$ & $0,2667 b$ & $0,1800 \mathrm{c}$ & $0,3300 \mathrm{~b}$ & $3,4967 b$ & 68,7300 & $29,5033 c$ \\
\hline AS1572YG & $0,1733 a$ & $0,7900 \mathrm{a}$ & $0,2600 \mathrm{~b}$ & $0,1667 d$ & $0,3267 b$ & $3,6367 b$ & 68,8767 & $28,3967 d$ \\
\hline AS1573YG & $0,1533 b$ & $0,6800 \mathrm{c}$ & $0,2200 \mathrm{c}$ & $0,1600 \mathrm{~d}$ & $0,2967 d$ & $3,6400 \mathrm{~b}$ & 67,6333 & $31,1167 b$ \\
\hline AS1578YG & $0,1733 a$ & $0,7700 \mathrm{~b}$ & $0,2633 b$ & $0,1867 b$ & $0,3367 b$ & $3,8133 \mathrm{a}$ & 69,4000 & $28,6133 \mathrm{c}$ \\
\hline DKB240YG & $0,1600 \mathrm{~b}$ & $0,8000 \mathrm{a}$ & $0,2500 \mathrm{~b}$ & $0,1767 \mathrm{c}$ & $0,3167 \mathrm{c}$ & $3,5867 b$ & 70,1500 & $27,8467 d$ \\
\hline DKB566YG & $0,1767 \mathrm{a}$ & $0,7933 \mathrm{a}$ & $0,2600 \mathrm{~b}$ & $0,1833 b$ & $0,3300 \mathrm{~b}$ & $3,5667 b$ & 69,6733 & $31,3400 \mathrm{~b}$ \\
\hline 2B604HX & $0,1933 a$ & $0,8467 \mathrm{a}$ & $0,2967 \mathrm{a}$ & $0,1967 \mathrm{a}$ & $0,3467 \mathrm{a}$ & $3,6500 \mathrm{~b}$ & 68,6800 & $28,6733 \mathrm{c}$ \\
\hline P30B39Y & $0,1733 a$ & $0,7567 b$ & $0,2567 b$ & $0,1900 \mathrm{~b}$ & $0,3300 \mathrm{~b}$ & $3,9233 a$ & 69,4500 & $30,4733 b$ \\
\hline P30F36Y & $0,1667 b$ & $0,7867 \mathrm{a}$ & $0,2633 b$ & $0,1867 b$ & $0,3300 \mathrm{~b}$ & $3,8667 \mathrm{a}$ & 70,2067 & $30,5333 b$ \\
\hline P30F53Y & $0,1800 \mathrm{a}$ & $0,7900 \mathrm{a}$ & $0,2600 \mathrm{~b}$ & $0,1900 \mathrm{~b}$ & $0,3300 \mathrm{~b}$ & $3,6700 \mathrm{~b}$ & 70,3033 & $30,9533 b$ \\
\hline P30F53H & $0,1767 \mathrm{a}$ & $0,7867 \mathrm{a}$ & $0,2667 b$ & $0,1900 \mathrm{~b}$ & $0,3367 b$ & $3,8067 \mathrm{a}$ & 70,6533 & $32,5733 \mathrm{a}$ \\
\hline P32R48Y & $0,1900 \mathrm{a}$ & $0,8367 \mathrm{a}$ & $0,2867 \mathrm{a}$ & $0,2000 \mathrm{a}$ & $0,3500 \mathrm{a}$ & $3,8400 \mathrm{a}$ & 70,3267 & $31,2400 \mathrm{~b}$ \\
\hline BG7060Y & $0,1933 \mathrm{a}$ & $0,8400 \mathrm{a}$ & $0,2900 \mathrm{a}$ & $0,2033 a$ & $0,3500 \mathrm{a}$ & $3,9233 \mathrm{a}$ & 71,3333 & $29,0300 \mathrm{c}$ \\
\hline AG8011YG & $0,1567 b$ & $0,7533 b$ & $0,2467 b$ & $0,1667 d$ & $0,3167 \mathrm{c}$ & $3,7333 b$ & 68,3733 & $28,8100 \mathrm{c}$ \\
\hline AG9020YG & $0,1833 \mathrm{a}$ & $0,8300 \mathrm{a}$ & $0,2733 \mathrm{a}$ & $0,1700 \mathrm{~d}$ & $0,3167 \mathrm{c}$ & $3,5433 b$ & 67,6900 & $29,3733 c$ \\
\hline BG8124YG & $0,1567 b$ & $0,7133 \mathrm{c}$ & $0,2367 \mathrm{c}$ & $0,1633 d$ & $0,3067 d$ & $3,6233 b$ & 69,1500 & $27,7300 \mathrm{~d}$ \\
\hline BG8418YG & $0,1733 a$ & $0,8133 a$ & $0,2633 b$ & $0,2033 a$ & $0,3433 a$ & $3,9667 \mathrm{a}$ & 69,4967 & $28,1233 d$ \\
\hline Número de grupos & 2 & 3 & 3 & 4 & 4 & 2 & - & 4 \\
\hline
\end{tabular}

* Médias de genótipos não seguidas pela mesma letra diferem pelo teste de Scott-Knott, a 5\% de probabilidade. ns = não significativo.

(2012), em estudo com 19 híbridos simples de milho, constataram variabilidade genética e produtividade de grãos na safra superiores às encontradas neste estudo $\left(7,93\right.$ a $\left.10,71 \mathrm{tha}^{-1}\right)$.
As oscilações ocorridas em cada variável nutricional entre os genótipos podem ser atribuídas às características genéticas, pois todos foram submetidos às mesmas condições de 
cultivo. Embora os grãos de milho sejam usados essencialmente como ingrediente energético na ração, variações em seu teor proteico, bem como na respectiva composição em seu perfil aminoacídico, podem causar efeitos significativos no metabolismo animal, os quais têm este cereal como ingrediente majoritário da dieta. O valor médio de proteína bruta $(7,63 \%)$ foi semelhante ao relatado em tabelas nacionais de composição de alimentos para animais, variando entre 6,97 e $8,11 \%$ (Tabela 2 ). Valor médio superior $(8,61 \%)$ foi encontrado por PIOVESAN et al. (2010) em trabalho realizado com 45 amostras de grãos de milho na região do Oeste do Paraná. Por outro lado, o perfil de aminoácidos obtidos neste estudo difere não só para as amostras analisadas (Tabela 2), mas também na comparação com outros relatos científicos, demostrando existir expressiva variabilidade entre genótipos, independente dos valores absolutos de proteína, o que é atribuído essencialmente à origem genética do genótipo.

Considerando sua característica majoritariamente energética, foi observada variação de $67,63 \%$ a $71,33 \%$ de amido (AMD), onde a fração de amilose (AML) variou de 27,73\% a $32,57 \%$ e o teor de extrato etéreo (EE) oscilou de 3,49 a $3,96 \%$ (Tabela 2). Isso demonstra que o milho pode ser usado em estratégias alimentares diferenciadas, pois, além das variações nos valores de amido, deve-se considerar que amilose possui digestão mais lenta do que a amilopectina, podendo causar alterações metabólicas e constitucionais expressivas no organismo animal. DENARDIN et al. (2009) observaram que dietas com maior proporção de amilopectina em relação à amilose causaram maior acúmulo de gordura epididimal em ratos, levantando a hipótese de que os animais, embora com mesmo ganho de peso, possam acumular maior teor de gordura corporal quando consumindo milho com menores teores de amilose, o que comprometerá o produto disponibilizado no mercado, uma vez que o consumidor procura alimentos mais saudáveis e com reduzido teor de gordura.

O diagnóstico de multicolinearidade, com base na matriz de correlação genotípica entre as 14 variáveis, apresentou número de condição (NC) igual a 1.552, o que caracteriza multicolinearidade severa, de acordo com MONTGOMERY \& PECK (1982). Nesse caso, não é recomendada a análise de agrupamento, pois as variáveis multicolineares contribuem com maior peso no agrupamento (CRUZ \& CARNEIRO, 2006). Mas, com a eliminação das variáveis THR, VAL, ILE, LEU, FEN, HIS e ARG, o $\mathrm{NC}$ reduziu para 74, indicando colinearidade fraca, o que possibilita proceder à análise de agrupamento de forma adequada.

Dentre as variáveis mensuradas, constatou-se que a AML, EE, CIS e LIS foram as que, nessa ordem, mais contribuíram para divergência genética pelo método de SINGH (1981), com valores de 34,76\%, 18,76\%, 15,51\% e $13,88 \%$, respectivamente. As demais variáveis TRP, PROD e PB contribuíram em menor proporção com valores de $6,93 \%, 5,53 \%$ e 4,63\%, respectivamente. Por meio do método de agrupamento da ligação média entre grupos (UPGMA), realizado com base na distância generalizada de Mahalanobis $\left(\mathrm{D}^{2}\right)$, calculada a partir das variáveis PROD, PB, LIS, CIS, TRP, EE e AML, foram formados quatro grupos, ao utilizar $70 \%$ como critério de dissimilaridade (Figura 1). O grupo 1 foi constituído por sete genótipos (P30B39Y, P30F36Y, P32R48Y, P30F53Y, P30F53H, AS1573YG, DKB566YG), o grupo 2 por dois genótipos (BG7060Y, BG8418YG), o grupo 3 por oito genótipos (DKB240YG, AG9020YG, BG8124YG, AS1578YG, AG8011YG, AS1551YG, 2B604HX, AS1555YG) e o grupo 4 por apenas um genótipo (AS1572YG) (Figura 1). Foi constatado que os agrupamentos servem de base para a orientação de cruzamentos entre genótipos de grupos distintos. O coeficiente de correlação cofenética (CCC) foi significativo $(\mathrm{P} \leq 0,05)$, com valor igual a 0,5788 , o que evidencia consistência do padrão de agrupamento. Estudo realizado por CARGNELUTTI FILHO \& GUADAGNIN (2011) evidenciou que o método UPGMA foi considerado o método mais eficiente no agrupamento de cultivares de milho.

A comparação de médias dos grupos, por meio do teste $t$ para amostras independentes, indicou que, em cinco (PB, CIS, TRP, EE, AML) das sete variáveis utilizadas no agrupamento dos genótipos, houve diferença significativa (Tabela 3). As variáveis PROD e LIS não apresentaram diferenças significativas entre os grupos. Diante disso, pode-se inferir que não só os caracteres agronômicos devem ser considerados em estudos de divergência genética em milho, mas também as variáveis nutricionais, devido aos grãos serem amplamente utilizados na alimentação animal. Na prática, como visto, o teor de amilose e o extrato etéreo foram as variáveis que mais contribuíram para a divergência genética e merecem mais atenção dos melhoristas. 


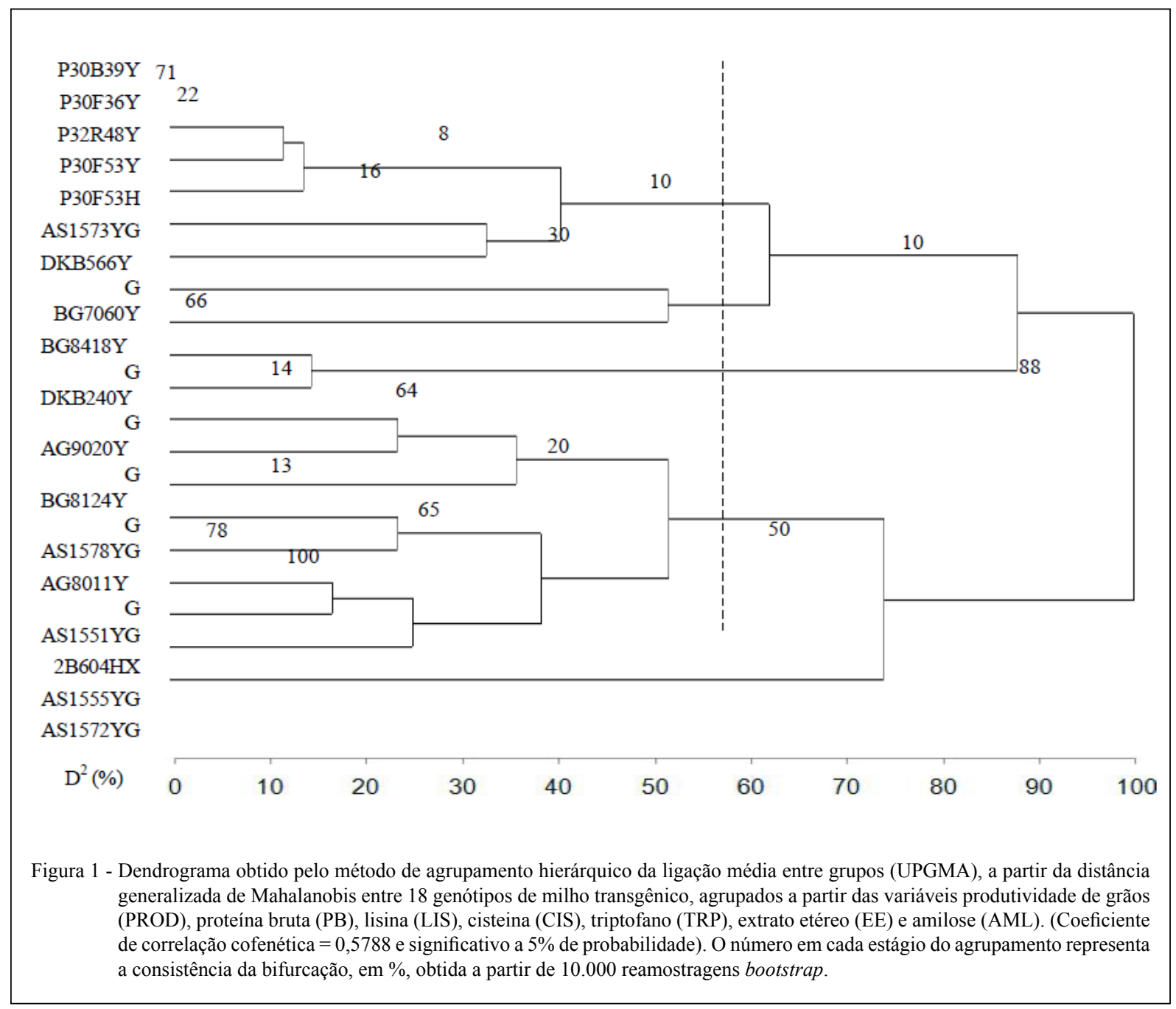

\section{CONCLUSÃO}

Há divergência genética entre os genótipos de milho transgênico. As variáveis amilose, extrato etéreo e cisteina foram, nessa ordem, as que mais contribuíram para a divergência genética. Com base nas variáveis produtividade de grãos, proteína bruta, lisina, cisteina, triptofano, extrato etéreo e amilose, os genótipos de milho transgênico avaliados foram distribuídos em quatro grupos.

Tabela 3 - Médias das variáveis produtividade de grãos (PROD, em tha ${ }^{-1}$ ), proteína bruta (PB, em \%MB), lisina (LIS, em \%MB), cisteina (CIS, em \%MB), triptofano (TRP, em \%MB), extrato etéreo (EE, em \%MB) e amilose (AML, em \%MB) para os 18 genótipos de milho transgênico alocados nos grupos formados por meio do método UPGMA.

\begin{tabular}{|c|c|c|c|c|c|c|c|c|}
\hline Grupo* & Número de genótipos & PROD & $\mathrm{PB}$ & LIS & CIS & TRP & $\mathrm{EE}$ & AML \\
\hline 1 & 7 & $6,75804 a$ & $7,57952 \mathrm{a}$ & $0,21238 \mathrm{a}$ & $0,16524 b$ & $0,04571 \mathrm{~b}$ & $3,75905 b$ & $31,17571 \mathrm{a}$ \\
\hline 2 & 2 & $7,06883 \mathrm{a}$ & $7,91667 \mathrm{a}$ & $0,21667 \mathrm{a}$ & $0,17667 \mathrm{a}$ & $0,04500 \mathrm{~b}$ & $3,94500 \mathrm{a}$ & $28,57667 \mathrm{c}$ \\
\hline 3 & 8 & $6,58912 \mathrm{a}$ & $7,61042 \mathrm{a}$ & $0,21458 \mathrm{a}$ & $0,16458 b$ & $0,04542 b$ & $3,64000 \mathrm{c}$ & $28,82958 b c$ \\
\hline 4 & 1 & $6,25705 a$ & $7,58667 \mathrm{a}$ & $0,22000 \mathrm{a}$ & $0,15333 \mathrm{c}$ & $0,05000 \mathrm{a}$ & $3,63667 b c$ & $28,39667 \mathrm{~cd}$ \\
\hline
\end{tabular}

${ }^{*}$ Para cada variável, médias de grupos não seguidas pela mesma letra, na coluna, diferem pelo teste t, a 5\% de probabilidade. 


\section{AGRADECIMENTOS}

Ao Conselho Nacional de Desenvolvimento Científico e Tecnológico (CNPq) e à Coordenação de Aperfeiçoamento de Pessoal de Nível Superior (CAPES), pela concessão de bolsas aos autores. A empresa Adisseo Brasil, na pessoa do Sr. Washington Neves, pela realização das análises laboratoriais e a Alexandra Pretto pelo auxílio nas análises laboratoriais. Aos alunos bolsistas e voluntários pelo auxílio na coleta de dados.

\section{REFERÊNCIAS}

ALVES, B.M. et al. Variability of grain productivity and energy profile of maize (Zea mays L.) genotypes. Journal of Cereal Science, v.60, p.164-171, 2014. Disponível em: <http://www. sciencedirect.com/science/article/pii/S0733521014000551>. Acesso em: 12 jun. 2014. doi: 10.1016/j.jcs.2014.02.007.

AYRES, M. et al. BioEstat: aplicações estatísticas nas áreas das ciências biomédicas. Belém: Sociedade Civil Mamirauá, 2007. $364 \mathrm{p}$.

BARROSO, L.P.; ARTES, R. Análise multivariada. Lavras: UFLA, 2003. 151p.

CALDARELLI, C.E.; BACCHI, M.R.P. Fatores de influência no preço do milho no Brasil. Nova Economia, v.22, p.141-164, 2012. Disponível em: <http://web.face.ufmg.br/face/revista/ index.php/novaeconomia/article/view/1669/962>. Acesso em: 28 mar. 2014.

CAMPOS, H. Estatística experimental não-paramétrica. 4.ed. Piracicaba: Departamento de Matemática e Estatística - ESALQ, 1983. 349p.

CARGNELUTTI FILHO, A.; GUADAGNIN, J.P. Consistência do padrão de agrupamento de cultivares de milho. Ciência Rural, v.41, p.1503-1508, 2011. Disponível em: <http:/www.scielo.br/ pdf/cr/v41n9/a9611cr3908.pdf >. Acesso em: 28 mar. 2014. doi: $10.1590 / \mathrm{S} 0103-84782011005000116$.

COLLI, W. Organismos transgênicos no Brasil: regular ou desregular?. Revista Universidade de São Paulo, n.89, p.148173, 2011. Disponível em: <http//http://rusp.scielo.br/pdf/rusp/ n89/11.pdf>. Acesso em: 06 jun. 2014.

CRUZ, C.D. GENES - a software package for analysis in experimental statistics and quantitative genetics. Acta Scientiarum Agronomy, v.35, p.271-276, 2013. Disponível em: $<$ http://periodicos.uem.br/ojs/index.php/ActaSciAgron/article/ view/21251/pdf $>$. Acesso em: 28 mar. 2014. doi: 10.4025/ actasciagron.v35i3.21251.

CRUZ, C.D.; CARNEIRO, P.C.S. Modelos biométricos aplicados ao melhoramento genético. 2.ed. Viçosa: UFV, 2006. V.2, 585p.

DENARDIN, C.C. et al. Amylose content in rice (Oryza sativa) affects performance, glycemic and lipidic metabolism in rats. Ciência Rural, v.42, p. 381-387, 2012. Disponível em: <http:// www.scielo.br/pdf/cr/v42n2/a3412cr2746.pdf $>$. Acesso em: 5 jul. 2014.
DOTTO, M.A. et al. Divergência genética entre cultivares comerciais de milho em baixas altitudes no Tocantins, safra 2007/2008. Revista Ciência Agronômica, v.41, p.630-637, 2010. Disponível em: <http://www.ccarevista.ufc.br/seer/index.php/ ccarevista/article/view/847/489>. Acesso em: 28 mar. 2014.

IDRIS, A.E. et al. Maize (Zea mays L.) Genotypes diversity study by utilization of inter-simple sequence repeat (ISSR) markers. Australian Journal of Basic and Applied Sciences, v.6, p.42-47, 2012. Disponível em: <http://www.sustech.edu/staff_ publications/20121226101801790.pdf>. Acesso em: 28 mar. 2014.

MARTINEZ, C.; CUEVAS-PEREZ, F. Evaluación de lacalidad culinária y molineradel arroz. 3.ed. Cali: CIAT, 1989. 75p.

MONTGOMERY, D.C.; PECK, E.A. Introduction to linear regression analysis. New York: John Wiley \& Sons, 1982. 504p.

PIOVESAN, V. et al. Predição do conteúdo de aminoácidos essenciais do grão de milho. Ciência e Agrotecnologia, v.34, p.758-764, 2010. Disponível em: <http://www.scielo.br/pdf/cagro/ v34n3/32.pdf $>$. Acesso em: 28 mar. 2014.

QAIM, M.; MATUSCHKE, I. Impacts of genetically modified crops in developing countries: A survey. Quarterly Journal of International Agriculture, v.44, p.207-217, 2005.

RESENDE, M.D.V.de; DUARTE, J.B. Precisão e controle de qualidade em experimentos de avaliação de cultivares. Pesquisa Agropecuária Tropical, v.37, p.182-194, 2007. Disponível em: <http://www.revistas.ufg.br/index.php/pat/article/ viewFile/1867/1773>. Acesso em: 28 mar. 2014.

ROTILI, E.A. et al. Divergência genética em genótipos de milho, no Estado do Tocantins. Revista Ciência Agronômica, v.43, p.516-521, 2012. Disponível em: <http://www.ccarevista.ufc.br/ seer/index.php/ccarevista/article/view/1412/713>. Acesso em: 28 mar. 2014.

SIMON, G.A. et al. Divergência genética em milho de primeira e segunda safra. Semina, v.33, p.449-458, 2012. Disponível em: <http://www.uel.br/revistas/uel/index.php/semagrarias/ article/view/5605/10437>. Acesso em: 28 mar. 2014. doi: 10.5433/1679-0359.2012v33n2p449.

SINGH, D. The relative importance of characters affecting genetic divergence. Indian Journal of Genetic and Plant Breeding, v.41, p.237- 245, 1981.

STEEL, R.G.D. et al. Principles and procedures of statistics: a biometrical approach. 3.ed. New York: McGraw Hill Book, 1997. 666 .

SUBRAMANIAN, A.; SUBBARAMAN, N. Hierarchical cluster analysis of genetic diversity in Maize germplasm. Electronic Journal of Plant Breeding, v.1, p.431-436, 2010. Disponível em: $<\mathrm{http}$ ://citeseerx.ist.psu.edu/viewdoc/download?doi=10.1.1.177.6 690\&rep=rep1\&type=pdf $>$. Acesso em: 28 mar. 2014.

ZHU, J.; KHAN, K. Effects of genotype and environment on glutenin polymers and breadmaking quality. Cereal Chemistry, v.78, p.125-130, 2001. 